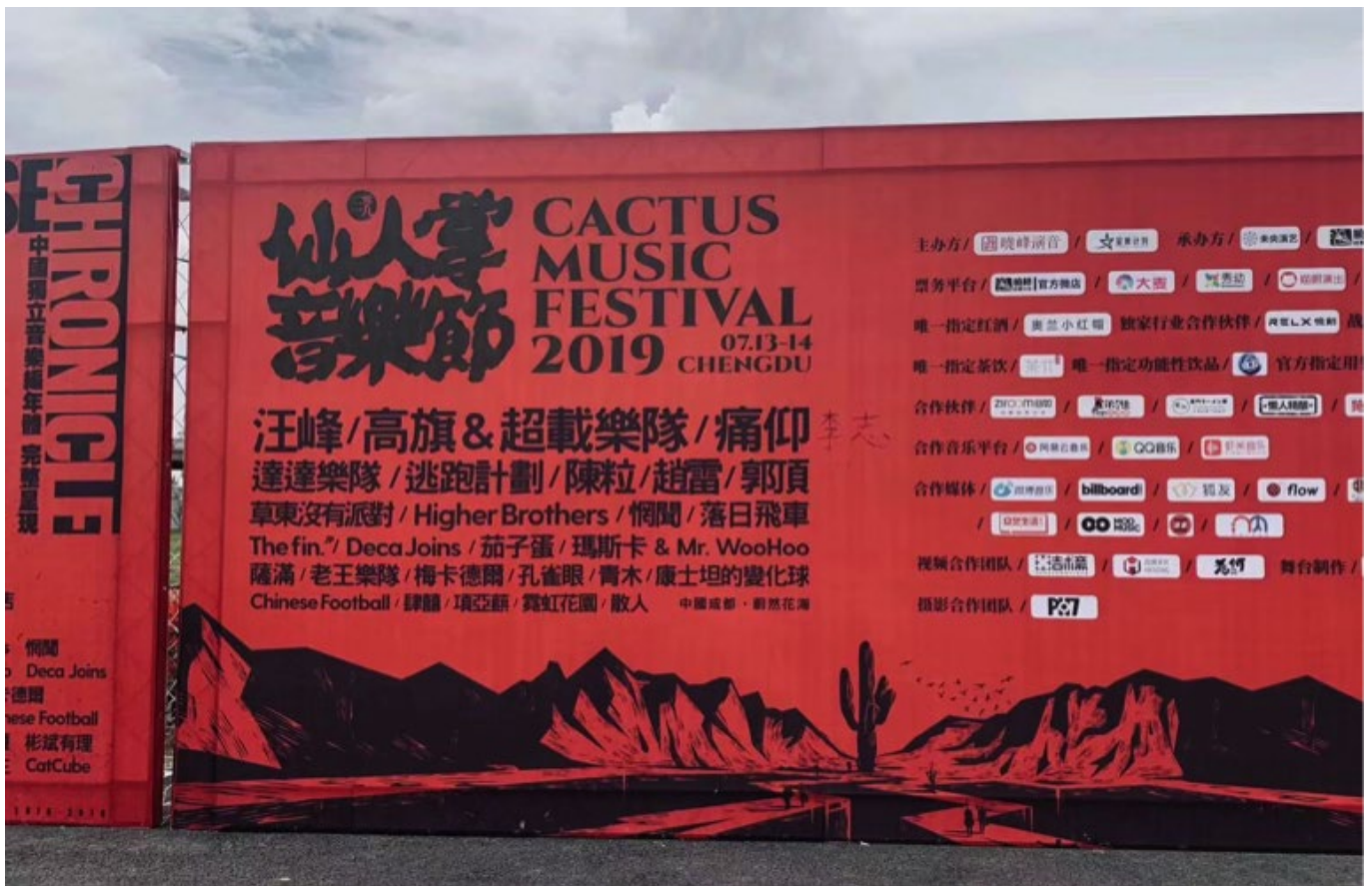

\section{From Rebellion to Erasure \\ The Rise and Fall of Urban Folk Rocker Li Zhi}

Jingyi WANG (Veronica)

Folk rock (民谣) has long been a popular subculture in contemporary China, historically playing a 'rebellious' spiritual role. This essay profiles folk-rock singer Li Zhi, who achieved widespread popularity before being banned for unknown reasons in April 2019. The case of Li Zhi showcases how the Partystate has been renegotiating its cultural legitimacy by coopting grassroots art and absorbing potentially subversive cultural elements into its own political 'spectacle'.

\begin{abstract}
Billboard for the prominent Catcus music festival that took place in Chengdu during July 2019 after the ban on Li Zhi. His name was added in handwriting by participants to 'remember' him. PC: Shelly Yiran Shi.
\end{abstract}

$\mathrm{n}$ the summer of 2019, underground rock subculture became an overnight sensation in China through a talent show called 'Summer of Bands' (乐队的夏天). What is notable about this resurgence is the role that the Party-state played in it. The quest of the Chinese authorities for soft power and cultural legitimacy, aimed at '[winning] the hearts and minds of the vast majority' (Zhao 2013, 27), resulted in a state-sponsored project of 'building cultural confidence' (建立文化 自信) that adopted the strategy of mobilising underground culture through media and market exposure. 
Unfortunately, it is still too early to celebrate the recognition of subculture in China. Although President Xi's 'cultural confidence' doctrine, proposed in 2012, marked an intensified connection between the political mobilisation of folk culture and grassroots creative agency, this relationship remains fraught with challenges and contradictions. This essay aims to showcase how the Partystate is renegotiating its cultural legitimacy by coopting grassroots art and absorbing potentially subversive cultural elements into its own political 'spectacle' (Debord 2005). However, cooptation also casts a long shadow of exclusion, as demonstrated in the fate of the folk-singer Li Zhi, who was suddenly banned from performing in April 2019 after his rise to stardom. This essay investigates the boundaries of cooptation in the $\mathrm{Xi}$ era by shedding light on increasingly tighter cultural control in the process of China's ongoing transition from the 'Harmonious Society' (和谐社会) of the $\mathrm{Hu}$ and Wen era (2003-13) to the 'Chinese Dream' (中国梦) of the current administration.

\section{China's Political 'Spectacle'}

To better understand the interwoven relationship between political authority and the culture industry in post-reform China, this essay draws on the concept of 'spectacle' that Debord proposed in 1967, when he critically observed that 'everything that was directly lived has receded into a representation' (Debord 2005, 7). Another key element of Debord's analysis is that the spectacle is almost immune to subversion: to critique it or to attempt to inject another substance into it will always lead to the trivialisation, sterilisation, and ultimately commercialisation of radical ideas. Though some scholars have been worrying about the visual-centred consumerist spectacle being ever-prevalent in China (Wu 2020), increasingly severe cultural governance and censorship has once again re-confirmed the primacy of politics in China's society. In such a society, the 'representation' of politics outweighs the 'reality' of politics.

While China's 'socialism with Chinese characteristics' is 'conceptually based on the continuities and discontinuities between [socialist traditions and neoliberal reform (Lin 2006, 1), the political spectacle in China is not reducible to a critique of capitalism. Xi's ubiquitous 'Chinese Dream' slogan and cultural retreat to Confucianism constitutes an overwhelmingly pervasive 'political spectacle' in which the 'dream' invokes ambiguity and nostalgia for ancient times (Chai and Chai $2013,95)$ and is capacious and pliable enough to absorb other critical discourses. The emerging 'political spectacle' created by Xi's power has moved from mostly coexisting with capitalism to essentially overriding capitalism, usurping its place as the hegemonic form of the spectacle itself.

\section{Folk Rock in China and Li Zhi}

Born in 1978, Li Zhi is an amateur artist who never received proper musical training. After obtaining his first guitar and being exposed to the music of Luo Dayou and Pink Floyd, he quit studying automation control at university to pursue a music career in 1999a rather common career trajectory for the current generation of Chinese subcultural musicians. An ethnographic study of these musicians indicates that amateur players were mostly attracted to rock because it is 'straightforward and simple' (Xiao, 2015, p. 81); more importantly, a skinhead player in the ethnography suggested in an interview that 'what we sang about was our true lives while foreign lyrics were just lyrics' (Xiao 2015, 93). Maybe it is because of this longing for singing about one's own true life, contemporary musicians in China are not satisfied by just 
performing 'foreign lyrics' as when rock first came to China, and some Chinese folk-rock songs make deliberate attempts to criticise contemporary social issues.

For example, the now-banned 'Chinese Kids' (中国孩子, 2007) by Zhou Yunpeng directly condemned several, well-known horrifying scandals involving the death of children. 'Don't be a kid in Karamay, where the fire burns your skin, breaking [your] mother's heart / Don't be a kid in the town of Shalan, where it's too dark in the water, you can't go to sleep ... In each line, the song directly speaks to unforgotten tragedies, be it the death of 288 school children in a theatre fire in Karamay, Xinjiang province, in 1994, when pupils were told to 'let the leaders walk out first', or a flash flood that hit Shalan, Heilongjiang province in 2005 (for the full interpretation of the song, see de Kloet 2010, 81). Yet while Zhou Yunpeng is still active in the mainland folk-rock scene, $\mathrm{Li}$ Zhi, who released songs such as 'The Square' (广场) and 'People Don't Need Freedom' (人民 不需要自由)-both alluding to the Tiananmen Square protests of 1989-has now been erased from the music market altogether. These arbitrary boundaries of censorship reflect decentralised local governance as instruments of the central government administrative strategy of control (Chung 2015, 38). While criticism levelled at local governments is tolerated and even sometimes addressed to exhibit the responsiveness of the central government, parody of the legitimacy of the central authority has become unacceptable in Xi's political spectacle.

Throughout his career, Li Zhi has always claimed to be a 'small town youth' (小镇青年). This claim evokes a very common experience of 'compressed modernity' (Chang 2010) and growing up amid the unprecedented speed and unevenness of urbanisation. As a result, his songs resonate with people composing a loose and fluid subculture of 'networks of people who come to share the meaning of specific ideas, material objects, and practices through interaction' (Williams 2011, 39). Li Zhi's music, although perhaps unassuming upon first listen, gives form to the power inequalities and regional 'uneven modernity' (Gong 2011) that define contemporary China.

\section{Songs of Place}

Li Zhi's 2014 album 1701 critically reflected on Chinese social phenomena caused, but also forgotten, by its neoliberal developmentalism, one of which being the nostalgia for 'place'. The song 'Hot River' (热河), titled after the name of a street in Nanjing, opens with the line 'Hot River Street is just like Jintan township in the 1980s', comparing the street to his birthplace in Jiangsu province, once a small settlement which has now become a district of the prefecture-level city Changzhou with a population of 560,000 residents. Whereas this figure seems large, it is much less than the average population of four million characteristic of Chinese prefecture-level cities, and further pales in comparison to megacities like Beijing or Shanghai. These numbers further cement the 'small town youth' identity that Li Zhi has always associated himself with; in 2009, 71 percent of the population lived in these 'small towns' (World Bank 2012, 10), which are administratively classified as 'urban' along with metropolitan centres.

Consequently, Li Zhi's memory of place, like many millions of Chinese 'small town youth', is vastly different from the memories of inhabitants residing in metropolitan cities. Li described his formative years in a television interview as challenging: 'During the early 1990s in my small town, my middle school was extremely chaotic ... My parents were illiterate or semi-illiterate, the whole town did not have any extracurricular books ...' (Jiafang 2015). In this interview he further confirms that his experience is a fairly common situation among other 'small town youth' who are his fans. Thus, it cannot be assumed that a person who was born and raised in these 'small urban towns', 
albeit formally holding an 'urban' hukou, shares the living experiences and cultural identity of residents in first-tier cities such as Beijing, Shanghai, or Shenzhen.

Well aware of this shared 'site of memory' of the 'small town youth', Li Zhi is a master of 'encoding' this memory into music, as evidenced by the lyrics of 'Hot River':

'On Rehe Street is / A barber shop that has been open for many years / No matter what hairstyle you want / You only need to pay five yuan / The boss and her younger sister sit on the chairs / Facing the mirror without saying a word / Their hometown is behind them / On the shore, in Anhui, Quanjiao

Beside the monument there is a shabby cinema / Walk five hundred meters north to Nanjing West train station / There are out-of-towners everyday / Getting lost between straight and curved lines / Out of breath, full of tears / Running, tripping, running ...

I have been in the city for 896 days / Rehe Street always has the same look ...'

These verse-like lyrics carefully portray Hot River Street as an urban ghetto or village for the migrant community. As a small-town migrant in Nanjing himself, this street is probably where Li Zhi spent 896 days with many others like him. Migration in China has become a 'rite of passage for young people', with the 'culture of migration' perpetuating itself among young children as they grow up with the expectation that migration is the endorsed goal, either for employment opportunities or for university education (Murphy 2002, 21). Li Zhi initially went to Nanjing for university, describing himself as 'lucky' while many of his other classmates just 'went with the flow and stopped studying' (Jiafang 2015). The lines 'The boss and her young sister sit on the chairs ... / Their hometown is behind them / On the shore, in Anhui, Quanjiao' explicitly mention the experience of migration that people from small towns shared; despite their hometowns being scattered across China, they have undergone a generation of development together with the country. Moreover, the lyrics 'out of breath and full of tears / Running, tripping, running' are a vivid portrayal of these migrants' 'practice of everyday life' (de Certeau and Rendall 1984).

\section{From 'Rebellious Spectacle' to 'Erased Noise'}

Many scholars have highlighted the importance of live performance as a cultural production medium. The live experience 'emphasises reality, naked textures and bearing witness' (Dai Jinhua, quoted in Inwood 2014, 15), and the requirement of physical presence heightens both the fluidity and the communicative potentiality in a show, creating 'a kind of aura, a coming together of breaths, sights, and sounds with which flat-screen arts cannot compare' (Huang Zhenlin, quoted in Inwood 2014, 16). Li Zhi is probably well aware of the mobilising nature of live events, and in 2017 his team announced plans for a nationwide tour titled 334 that would have taken place over the following 12 years. The initiative was so named for the goal of travelling to and performing at all of the 334 prefecturelevel cities of China-most of them fourth- and fifth-tier 'small towns' unknown to the general public-after having performed at virtually all economically advanced cities.

Ever since Deng Xiaoping famously uttered 'let some people get rich first' during his South China Tour in the 1990s, China's dazzling economic developments have attracted global attention to its glamourous cities. For instance, Beijing is the site for practicing national identity and Shanghai the object of global consumerism (Visser 2010). On the contrary, smaller Chinese cities that may not have achieved global status 
are examined and presented by some artists as a 'world without a future', as in the films of Jia Zhangke (Bordeleau 2010). These 'small towns' often only appear as the 'hometown' of the hundreds of millions of peasant workers floating and following the 'blind flow' (盲流) of migration, mere sites of departure, places to be escaped from. As Yi-Fu Tuan, a ChineseAmerican geographer who is known as the 'father' of humanist geography, highlighted: a space transforms into a meaningful 'place' by 'spatial feelings and ideas in the stream of experience' (Tuan 1979, 388), and a place is 'defined by how bodies come to make meaning out of, form attachments to and navigate within spatial environments' (Tuan, in Xiao 2018, 39-40). Per his logic, we can say that these Chinese 'small towns' targeted by Li Zhi have been inadvertently reduced to 'non-places' or non-meaningful places, entangled between globalised cities and the nostalgically imagined agricultural rural, impotent in providing attachable cultural images for their people. By becoming administratively classified as 'cities', these towns have given up agricultural land and adopted 'speculative urbanisation' (Shin 2016), resulting in them being squeezed out of the Chinese dichotomy of spatial symbols.

In aiming for the 'decentralising' of his critical folk rock to these 'neglected' small towns, Li Zhi's 334 touring project carries two key implications that can be interpreted as rebellion against the Chinese 'political spectacle'. Firstly, the power of 'live performance discourse' is wielded as 'an expression of resistance against the perceived discursive power (huayuquan)-or gatekeeping authority' (Inwood 2014, 18) that is delegated to local levels of government. Although scholars have argued that globalised capital, neoliberal desires, and transnational modernity are constantly intertwined and complementary with state authorities in big cities (for example, see de Kloet \& Scheen 2013; Lu 2001 and 2007; Meng 2018), the control of discursive power in local government areas across China is subject to more state intervention (Chung 2015). Explaining his reasons for embarking on the 334 tour at his show in Shandong, Li Zhi remarked: 'We hope we can go to these more remote, so-called third- and fourth-tier cities, play there, and give you guys some courage. [We want to] maintain the locality of the "venue", because for underground music, the venue is number one; without the locality of the venue, how can you see this kind of show here?' (Three Three Four Project 2017). If immersing themselves in rock music provides urban youth in the cultural North of Beijing with 'cosmopolitan poses' and 'the potential to realise social and political change' (de Kloet 2010, 15 and 202), then what Li Zhi is doing is bringing such flexible subjectivities down to the 'local China' comprised of these small towns that are yet to catch up with global trends, a choice that to a certain extent poses a challenge to the highly centralised 'political spectacle'. Indeed, his exclusion of 'directly-administered municipalities' during his tour may well be a deliberate attempt to 'decentralise' or even 'alter' the cultural hegemony of state endorsement.

Yet, considering how both local markets and local authorities have displayed a striking ability to coopt independent artists, the ban on Li Zhi sent a warning signal about the boundaries between state and market, a reminder of the power relations between spontaneous folk culture and the 'political spectacle'. This is not to suggest that the widely conceptualised cooptation strategies of commodification and the institutionalisation of folk culture, both aimed at depoliticising society, have been rendered void. Instead, I suggest that the contemporary Chinese cultural scene should be reevaluated from the perspective of the decoding and reproduction processes enacted by the audience in this rapidly changing era. At an afterparty following Li Zhi's show in Jining, Shandong province, the head of the Shandong 334 fan group said:

'In Jining, this fourth-tier city, there are no live music performances nor rock music. Li Zhi said today that for young people living in a less-developed city, other than eating. 
drinking, and playing mah-jong, I hope there are more shows like this in Jining (Three Three Four Project 2018).

Another fan from a rural area added:

'I believe this world will be better. My family is from a rural village ... All the money used to buy mly show ticket and transport fees, I earned all by myself ... When Li Zhi was performing inside, I was drinking by the door. Just by the door, that's where my utopia is; just by the door of Li Zhi's live performance, that's where my utopia is ...' (Three Three Four Project 2018).

When an off-screen voice asked 'So do you really believe that performing travelling shows like he is doing, city by city, would change the local youth?', all the fans answered 'Yes, it will definitely make changes', and began singing $\mathrm{Li}$ Zhi's signature song 'Has Man a Future' (这个世 界会好吗). Following the rural fan's passionate pursuit of his 'utopia', this very touching scene seems to affirm Chinese rock star Cui Jian's assertion that 'rock is an ideology, not a set musical form' (Jones 1992, 115).

\section{A New Utopia}

When investigating Chinese popular music of the 2000s, de Kloet wrote: 'We are living in a world characterised by an absence of a utopia outside, it becomes all the more urgent to think through the political and social possibilities emerging from within the systems in which we are living' (de Kloet 2010, 202). The reception of Li Zhi's music marks the emergence of a 'utopia' from under the hegemonic cultural system and the 'political spectacle'-at least from the perspective of those small town youth whose subjectivities are desperate for change. Rock music had once 'reached and influenced the political behaviour of a far larger audience' before and during the student movements of 1989, with Cui Jian serving as a symbolic figure whose performances enacted 'a collective ritual of resistance' (Wasserstrom and Perry 1992, 152).

Comparing Li Zhi's fan club with Cui Jian's pre-1989 audience reveals a corresponding function of constructing a 'utopia' from the artists' music, or rather an 'ideology' for their supporters. Whereas listeners of Cui Jian's music were mostly college students and urban workers, the demographics of Li Zhi fans are slightly more complex. Not only have young migrants to urban areas been mobilised by his songs of desire and place, more urban subjects have also become attracted to this underground idol through the mass commercialisation and cooptation of his music. Given that grassroots resistance of all forms has become a rising problem for local governance across China (Zhang and Lee 2019), there is reason to believe that with the local inroads of the 334 project, the fear of the 'change' that Li Zhi's ideology struggled to promote led to his sudden erasure from the scene. 
This text is taken from Made in China Journal: Volume 5, Issue 1, 2020, edited by Ivan Franceschini, Nicholas Loubere and Christian Sorace, published 2020 by ANU Press, The Australian National University, Canberra, Australia.

doi.org/10.22459/MIC.05.01.2020.18 